\title{
OS PROFISSIONAIS DO SOBRENATURAL: MÁGOS, GÓES E PHARMAKEÚS
}

\author{
Dulcileide V. do Nascimento Braga* \\ (Universidade do Estado do Rio de Janeiro)
}

\begin{abstract}
RESUMO: O presente artigo objetiva, ao pressupor que as ações mágicas constituem práticas passíveis de aprendizado, apresentar a análise da estrutura vocabular dos termos que classificam os profissionais da magia. Busca-se, também, a partir da tradição míticoliterária grega, demonstrar que tais profissionais têm uma prática registrada em diversos períodos da literatura grega e influenciaram ações que extrapolam o viés temporal.

Palavras-Chave: Téchne mágica; Mágos; Góes; Pharmakeús.
\end{abstract}

\section{THE SUPERNATURAL PROFESSIONALS: MÁGOS, GÓES AND PHARMAKEÚS}

\begin{abstract}
This article aims, assuming that magical actions constitute practices that can be learned, to present the analysis of the vocabulary structure of the terms that classify magic professionals. It is also sought, from the greek mythical-literary tradition, to demonstrate that these professionals have a practice recorded in several periods of greek literature and influenced actions that go beyond the temporal bias.
\end{abstract}

KEYWORDS: Téchne magic; Mágos; Góes; Pharmakeús.

Magia, do grego mageía, segundo Tupet (1976, p. X), é a prática exercida, através de palavras e gestos, por um indivíduo que detém certos conhecimentos, que o capacitam a produzir resultados de toda ordem. George Luck (1995, p. 35) precisa essa definição ao afirmar que a magia é uma técnica cuja crença se baseia nos poderes localizados na alma humana e no universo e que pretende impor a vontade humana sobre a natureza ou sobre os seres humanos.

Platão, em Leis XI, 932e-933b, já enumera os principais procedimentos mágicos, no séc. IV a.C., e a difícil tarefa de analisar essa técnica:

Quanto aos malefícios que uns podem causar aos outros por meio de drogas (pharmákois) já tratamos dos de consequências letais; mas ainda não falamos dos incômodos provocados intencionalmente e com premeditação por meio de bebidas e alimentos ou com unguentos. O difícil na presente exposição é que há no gênero humano duas espécies de envenenamento: uma é a que acabamos de nos referir, e que consiste em causar dano ao corpo pela ação natural de outros corpos; a outra, por meio de sortilégios (magganeíais), encantamentos (epoidaîs) e o que se denomina ligadura (katadésesi), chega a persuadir aos

\footnotetext{
*E-mail: dulcinascimentobraga@gmail.com
} 
que querem causar danos a terceiros que o conseguirão com tal recurso, como também convence a estes últimos que ninguém lhes pode ocasionar tanto mal como as pessoas conhecedoras de artes mágicas. O que possa haver de verdadeiro em tudo isso não é fácil conhecer, nem depois de sabido, deixar aceitável para ninguém; dada a desconfiança reinante nos espíritos a respeito de tais assuntos, não vale a pena procurar convencê-los, sempre que encontrarem na porta de casa bonequinhos de cera, ou em encruzilhadas, ou talvez mesmo sobre a sepultura de seus antepassados, de que não devem dar a menor importância a essas práticas, pois acerca de tudo isto ninguém têm opinião formada.

É relevante destacar que o conceito de pharmakeía utilizado por Platão não se restringe exclusivamente ao uso de um phármakon (bebidas, alimentos ou unguentos), mas se prolonga através de sortilégios, encantamentos e ligaduras.

Platão ainda questiona a eficácia dessas profissionais de magia cujas habilidades eram difíceis de se averiguar, analisar ou compreender, sendo a profissional julgada pela eficiência ou pelos danos causados por sua prática.

$\mathrm{O}$ fato de atribuir aos praticantes de magia um caráter perigoso, por conta do saber que detinham, e a necessidade de que essas práticas fossem controladas por leis, remetemnos aos diversos processos de impiedade sofridos por mulheres praticantes das téchnai mágicas. Dentre elas, destacamos o nome de três mulheres: a hetaira Frinea de Thespis, que foi acusada, pelo seu amante Euthias, de utilizar lugares sagrados para a prática de atos ilícitos e por ter formado um thíasos $^{1}$ sem a autorização legal dos atenienses; a sacerdotisa Teoris de Lemos, acusada de produzir phármaka para curar a epilepsia, e ainda temos o processo sofrido pela sacerdotisa Ninos, baseado nas mesmas acusações direcionadas às duas mulheres citadas anteriormente.

Tais atitudes eram consideradas desvios à ordem instituída pela pólis, que determinava que qualquer ação envolvendo contato direto com uma divindade ou com os mortos requereria a presença de um sacerdote, instituído pela cidade e responsável por impedir qualquer prática que pudesse contaminá-la de alguma maneira.

Maria Regina Candido (2003, p. 169) informa-nos sobre as práticas dessas mulheres:

\begin{abstract}
Acreditamos que Teoris de Lemos, assim como Frinea de Thespis, difundiam a crença na possibilidade de o homem efetuar, de maneira direta, a sua relação com as potências sobrenaturais e controlar os processos mais complicados que envolvem a vida, como doenças, inimizades e má sorte, de maneira eficaz e segura. Receitavam banhos, infusões com ervas e oferendas às divindades ctônicas, estimulavam os praticantes a fazer incursões pelo mundo de seres sobrenaturais, como os mortos. $\mathrm{O}$ mundo dos homens deixava de atender às necessidades do cotidiano, e a alternativa era solicitar auxílio das potências sobrenaturais.
\end{abstract}

Assim como Platão, Candido acredita que a punição relacionada a estas práticas e a seus praticantes esteja baseada no resultado advindo das mesmas, que nem sempre acarretava proveito àquele que solicitava um benefício mágico. Portanto, por temer a extensão do poder dessas práticas, os atenienses puniam seus praticantes, na maioria dos casos, mulheres estrangeiras, como uma forma de se precaverem.

Também salientamos que, apesar de a prática mágica ser, em determinadas circunstâncias, apontada como uma atividade marginal ou uma forma de corromper a religião políade, como mencionamos anteriormente, os praticantes destas téchnai

\footnotetext{
${ }^{1}$ Palavra utilizada para designar um grupo de pessoas que celebram um deus, normalmente, com festas, cantos e banquetes.
} 
detinham um conhecimento e um poder cuja eficácia seria sustentada por uma crença coletiva e por uma dependência de uma ordem moral que buscava a autoproteção, fato que garantia a continuidade das diversas formas de magia em todas as classes da sociedade helênica, como afirma o texto de Luck (1995, p. 42):

Pode a magia antiga se basear em ideias "primitivas", mas a forma em que nos
foi transmitida não era de nenhum modo primitiva. Pelo contrário, a magia,
nesse sentido, existiu somente dentro de culturas altamente desenvolvidas e
constituiu uma parte importante delas. Não só as classes baixas, os ignorantes
e incultos criam nela, mas, até o final da Antiguidade, os "intelectuais"
estiveram convencidos de que poderosas forças sobrenaturais atuavam em
torno deles, podendo ser controladas por certos meios.

Em grego, destacamos três termos para designar os detentores das artes mágicas: mágos, góes e pharmakeús.

O nome mais comumente utilizado para designar a feiticeira é mágos, cognato de mageía, magia. Segundo Pierre Chantraine (1984, v. mágos), esta palavra constitui um empréstimo iraniano e no plural, mágoi, designa uma das tribos dos Medos, como narra Herôdoto, I, 101: "Deioces unificou a nação dos Medos, governando-a. A Média era composta de diferentes povos: os Busos, Paretacenos, Estrucatos, Arizantos, Budios e os Magos"

Segundo ainda o relato de Heródoto, há entre os mágoi aqueles que têm a função de ser "intérpretes de sonhos". Podemos verificar esta atribuição dos magos em História I, 107: Astíages, após ter um sonho, solicitou aos magos, intérpretes de sonhos, que revelassem o seu significado; em I, 120, Astíages, para decidir a sorte de Ciro, mandou chamar os mesmos magos que anteriormente tinham interpretado o seu sonho; em I, 128 vemos isso quando Astíages manda empalar os magos, intérpretes dos sonhos, que o haviam convencido a deixar Ciro partir. No livro VII, 37 há uma passagem que ratifica a função de intérprete dos sonhos aos magos. Nela, Xerxes, após ver um eclipse solar, acreditando ser um mau presságio, pede aos seus magos que interpretem o fenômeno. Segundo Graf (1994, p. 30), além de serem intérpretes dos sonhos, os mágoi seriam os responsáveis pelos sacrifícios reais, pelos ritos funerários e pela adivinhação.

O termo mágos parece ter adquirido, com o advento da filosofia, conotação negativa, sendo, então, utilizado para estigmatizar opiniões e comportamentos considerados socialmente desviados, a julgar por Heráclito, frag. 14, que associa mágoi aos "vagabundos da noite, bacantes, mênades e aos mistos" e acredita serem esses homens merecedores de morte, posto que praticam ações ímpias. Graf (1994: 32) discute se esta caracterização de Heráclito reproduziria a atuação dos mágoi, pois se ela corresponder à realidade, este termo semanticamente poderá ganhar a conotação dos termos agúrtes e mántis, pedinte e adivinho, utilizados por Platão, na República, II-364b, ou ser interpretada a partir da expressão utilizada no papiro de Derveni, profissional dos ritos. Com base nesta definição, poderíamos afirmar que Heráclito, ao utilizar a expressão "vagabundos da noite", estaria dizendo que os mágoi seriam especialistas de toda uma série de ritos privados e secretos, como nos afirma o próprio Graf (1994, p. 33): "Para um jônico do fim do período arcaico, o mágos era semelhante aos especialistas itinerantes dos cultos privados, homens à margem da sociedade, ridicularizados por uns e, secretamente, temidos por outros"

Outro termo utilizado para nomear o praticante da magia é goés, termo cognato do verbo goáo, gemer, lamentar-se, e que inicialmente designava um cantor que proferia um lamento ritual pelos mortos, ou seja, o goés é aquele que "combina o êxtase com um 
lamento ritual e a cura ritual com a adivinhação" (GRAF, 1994, p. 35), e que mantém uma relação estreita com o mundo dos mortos.

Formadas a partir da mesma raiz, encontramos as palavras goeteía, magia, assim como goéteuma, procedimento mágico, fascinação. Heródoto (II, 33), ao narrar a história de Etearco, o amônio, aplica o termo góetes para informar-nos sobre a crença, por parte dos nasamones, de que os habitantes de uma cidade em que entraram eram feiticeiros; e em IV, 105, discorre sobre os relatos que afirmam que todos os Neuros eram goétes.

Encontramos ainda o termo góes, associado a epoidos, cantor, aquele que canta palavras mágicas para curar, por exemplo, em Eurípides, As Bacantes, 234-235, em que encontramos os dois termos, na fala de Penteu, para fazer referência ao estrangeiro que está propagando o culto a Dioniso: "Dizem que veio um forasteiro feiticeiro cantor (góes epoidós) da terra da Ídia".

Em Platão, Leis 903b, quando a personagem chamada Ateniense ao mencionar que irá convencer alguém por meio de argumentos, diz: "Mas, ainda precisamos acrescentar algumas histórias, a fim de imobilizá-lo com o encantamento (epoidôn) que lhes é próprio". E, da mesma maneira, é associado a mágos no Elogio à Helena, de Górgias, ao evocar o poder da arte goética, que encanta, persuade e transforma. Essas técnicas associadas à magia, segundo o sofista, seriam técnicas do engano, pois desvirtuariam a alma e a opinião com falsas ilusões. Desse modo, Górgias defende Helena dizendo que ela foi vítima da persuasão mágica de Páris, contra a qual não haveria defesa.

O terceiro nome é pharmakeús ou pharmakós e designa um preparador de drogas, feiticeiro, ou, por ser cognato de pharmakeúo, significa, simplesmente, aquele que dá um remédio ou veneno a alguém, ou aquele que realiza uma operação mágica. Há ainda o termo pharmakís, -idos atribuído à mulher que prepara poções ou à feiticeira. Aristófanes, em As Nuvens, 749, utiliza esta palavra como qualificativo para a mulher. A expressão gunaîka pharmakída, encontrada em Aristófanes, refere-se a uma feiticeira da Tessália que fazia a lua baixar à noite, prendendo-a em um espelho.

Cabe-nos, contudo, falar um pouco mais da magia das palavras ou do encantamento. Como já mencionamos, o termo goés tem sua função e significado associado ao termo epoidé que revela a natureza mágica do emprego da palavra e traz em sua composição o termo aoidé, canto, que por sua vez está relacionado com o termo audé, voz humana. O grego distingue a linguagem humana, audé, do termo phoné que tanto pode representar a linguagem humana como o som produzido por um animal.

Pierre Chantraine (v. aeidô) assinala que o prefixo epi- destaca o valor mágico do canto, assim epoidé significa "canto ou palavra mágica".

É notório, entretanto, que o canto faz parte da cultura grega, seja através do maior aedo de todos os tempos, Homero, através do teatro, da vida privada ou da pública. O que diferencia, portanto, essas utilizações da arte mágica das goetés? A diferença está na estrutura destes encantamentos, na tonalidade com que as palavras eram pronunciadas, na junção de sílabas estranhas apresentadas como verdadeiras fórmulas mágicas, bem como aos poderes e divindades invocadas. Tal estrutura é apresentada no seguinte fragmento: "Febo, o que auxilia na adivinhação, vem contente, filho de Leto, arqueiro infalível, protetor do mal, venha aqui, neste momento! Vem! Vaticinador, dá-me teus oráculos durante a noite: allala, allala, santalala, talala”. (PGM, II).

As fórmulas mágicas, do ponto de vista formal, portanto, tinham uma estrutura pré-estabelecida (pronunciada e realizadas de uma determinada maneira) que consistem em uma série de instruções que foram transmitidas através do processo de iniciação. Esse processo de aprendizado pode ser no âmbito familiar ou em lugares considerados sagrados. 
Temos diversos registros de fórmulas mágicas, algumas, por exemplo, denominadas eróticas, objetivam a realização do desejo de um solicitante, e têm, basicamente, a mesma estrutura. Como exemplo, cito o PGM IV, 3:

\begin{abstract}
Que fulana me ame, a mim fulano filho de cicrano, que ela não tenha relações sexuais, nem por frente, nem por trás, nem busque prazer com outro homem, somente comigo; de modo que fulana não possa beber, nem comer, nem amar, nem sofrer, nem ter saúde; que não consiga dormir sem mim; ....arrasta a fulana pelos cabelos, as entranhas, sua alma em cada momento de sua vida... até que venha até mim e permaneça inseparavelmente unida a mim.
\end{abstract}

Neste encantamento se invoca o espírito de um morto ou de uma divindade, normalmente Tífon, Selene ou Hécate, mas quando se trata de magia erótica se invoca especialmente a deusa Afrodite e seu filho Eros. Essas práticas são acompanhadas de um gesto do solicitante, como, por exemplo, um suspiro diante da mulher desejada, um beijo na lâmina que contém o pedido, ou a simples repetição do nome de Afrodite.

Teócrito, no Id́líio 2, com 166 versos, demonstra-nos como essas fórmulas eram utilizadas ao narrar a história de como Simeta executa um ritual mágico com o intuito de reconquistar o amor de Délfis, um jovem atleta que a trocou por um novo amor. Eis alguns versos do poema:

Três vezes faço uma libação e três vezes, Soberana,

Pronuncio estas palavras: quer seja mulher, quer seja homem,

Que com ele dorme agora, que um tão grande esquecimento invada

Délfis como aquele que - ao que dizem - fez Teseu esquecer, um

Dia, Ariadne de belas tranças. (43-47)

Essa "técnica" das palavras também faz parte da tradição de uma literatura médica, pois além de apresentar vários deuses responsáveis pela cura, tinha um deus específico para a medicina, Asclépio, e um lugar de cura, Epidauro. Asclépio tinha um poder de cura muito grande, acreditava-se que ele, inclusive, podia ressuscitar os mortos. $O$ filho de Apolo curava a uns com as doces palavras da magia (contos, poemas e música), a outros oferecia poções eficazes, ou lhes aplicava ervas em torno de seus membros, ou cortava o mal com o ferro, para devolver-lhes a saúde.

A tradição médica incluía uma mistura de curas que podiam genuinamente ser observadas e uma medicina popular considerada mágica. Uma parte dos que exerciam a medicina mágica eram mulheres, embora a maioria delas trabalhasse como parteiras.

Os templos de Asclépio foram encontrados em todo o mundo mediterrâneo. Nesses templos, o processo de cura consistia mais em repouso, massagem e uma dieta modificada, do que aquilo que poderíamos chamar de medicina. Um método de cura que se tornou conhecido foi a "incubação", em que o doente dormia confinado no templo de Asclépio, na esperança de receber uma revelação daquele deus por meio de sonho. Aqueles que haviam sido curados faziam contribuições especiais para os templos, que frequentemente incluíam reproduções de gesso de quaisquer partes de seus corpos que tivessem sido curadas. Estes eram colocados em exibição como testemunhos do poder de cura do deus.

Um relato que corroborou esse processo foi o de Élio Aristides, orador e também um portador de doença crônica que no século da nossa era, em seus Hieroì Lógoi, nos dá uma visão da necessidade que as pessoas tinham pela cura, bem como os métodos empregados para esse fim. Depois tentar vários procedimentos médicos, Aristides tornouse um devoto de Asclépio. As curas prescritas para ele nos sonhos incluíam ações como: banhar-se em um rio agitado durante o inverno, derramar lama em si mesmo antes de se 
assentar no pátio do templo, andar sem sapatos todo o inverno e fazer sangria de várias partes do seu corpo.

A técnica mágica, portanto, ao longo da história foi um recurso utilizado como tentativa de controlar o mundo natural através de forças consideradas sobrenaturais. Essa técnica era ensinada somente aos iniciados e envolviam a arte da adivinhação, o preparo de feitiços e poções, a realização de rituais e cerimônias, bem como a maneira correta de se invocar deuses e espíritos. Quando realizados dentro dos templos, tais procedimentos eram considerados parte da religião. Quando realizados fora, eram classificado como magia.

A ideia de inferioridade feminina que perpassa toda a história não tem registro de quando começou. Desde a Antiguidade, temos concepções como a de Pitágoras que relacionava a mulher ao lado negativo ao dizer que: "Há um princípio bom que criou a ordem, a luz e o homem, e um princípio mau que criou o caos, as trevas e a mulher" (PITÁGORAS apud BEAUVOIR, 1997, p. 6).

Os elos que ligaram a imagem da mulher ao obscuro, ao caos e ao infortúnio masculino, foram delineados e reforçados por figuras arquetípicas como Pandora, Lilith e a própria Eva. Da mesma maneira, as goetés foram chamadas de charlatães quando não obtinham o resultado desejado ao evocarem os deuses e tentarem por técnicas diversas atender à solicitação de alguém que recorria às práticas mágicas para resolver problemas particulares. Essas solicitações, normalmente, envolviam uma ação que prejudicaria alguém, fato que serviu para atenuar a fama negativa das goetés.

Ainda hoje, encontramos aspectos desse tipo de comportamento mágico presentes nos procedimentos considerados mágico-religiosos ou na própria literatura ficcional que demonstram a força da seleção vocabular e da sonoridade provocada pela repetição de palavras e desejos com o único objetivo de concretizar desejos nem sempre passíveis de serem expressos em outras circunstâncias. Este é o caso da poesia citada abaixo:

\title{
A VOLTA DA MULHER MORENA, Vinicius de Moraes
}

\author{
Meus amigos, meus irmãos, cegai os olhos da mulher morena \\ Que os olhos da mulher morena estão me envolvendo \\ E estão me despertando de noite. Meus amigos, meus irmãos, cortai os lábios \\ da mulher morena Eles são maduros e úmidos e inquietos \\ E sabem tirar a volúpia de todos os frios. \\ Meus amigos, meus irmãos, e vós que amais a poesia da minha alma \\ Cortai os peitos da mulher morena \\ Que os peitos da mulher morena sufocam o meu sono \\ E trazem cores tristes para os meus olhos. \\ Jovem camponesa que me namoras quando eu passo nas tardes \\ Traze-me para o contato casto de tuas vestes \\ Salva-me dos braços da mulher morena \\ Eles são lassos, ficam estendidos imóveis ao longo de mim \\ São como raízes recendendo resina fresca \\ São como dois silêncios que me paralisam. \\ Aventureira do Rio da Vida, compra o meu corpo da mulher morena \\ Livra-me do seu ventre como a campina matinal \\ Livra-me do seu dorso como a água escorrendo fria. \\ Branca avozinha dos caminhos, reza para ir embora a mulher morena \\ Reza para murcharem as pernas da mulher morena \\ Reza para a velhice roer dentro da mulher morena \\ Que a mulher morena está encurvando os meus ombros \\ E está trazendo tosse má para o meu peito. \\ Meus amigos, meus irmãos, e vós todos que guardais ainda meus últimos \\ /cantos \\ Dai morte cruel à mulher morena!
}


O texto de Vinícius dialoga com o texto de Platão, citado anteriormente, em que faz menção às bonequinhas de cera utilizadas para fazer magia. A finalidade dessas bonecas, conhecidas posteriormente por bonecas de vodu, era, gradativamente, extinguir a funcionalidade de determinados órgãos (cegar, calar, impedir de andar, roer por dentro) até provocar a morte: "daí morte cruel à mulher morena".

O princípio "se não é meu não será de mais ninguém" está implícito em inúmeros encantamentos contidos nos PGM e representa, não só o desejo daquele/a que foi abandonado/a de se vingar de quem o/a abandonou, como também o desejo de se livrar daquele/a que emocionalmente lhe causa mal.

A voz humana é, portanto, o instrumento que potencializa a força do pensamento, concretizando-os através das palavras.

Portanto, a palavra, quer cantada, pronunciada em forma de versos, ou balbuciada em forma de encantamentos ou fórmulas invocatórias, faz parte do universo sonoro grego como forma de perpetuar segredos e manifestar um poder.

Ainda hoje tentamos aprender sobre esta téchne que capacitava o indivíduo a concretizar desejos, entretanto esbarramos nas lacunas temporais, míticas e religiosas, cujas entrelinhas foram desfeitas com o passar dos anos e que, intencionalmente, ou não, desabilitaram a humanidade a obter o desejado com a mesma constância com que eram obtidas no passado.

Os ritos religiosos continuam a utilizar a magia das palavras, mas algumas palavras tornaram-se impronunciáveis e permanecem trancafiadas nas prisões silenciosas do descaso, cabe, portanto, a nós pronunciá-las, ou não, reconhecendo a influência que os profissionais da magia tiveram e têm nas ações atemporais denominadas sobrenaturais.

\section{REFERÊNCIAS}

BEAUVOIR, Simone de. O segundo sexo. 11. ed. Rio de Janeiro: Nova Fronteira, 1997.

BERNAND, André. Sorciers Grecs. France: Librairie Artthème Fayard, 1991.

DICKIE, Mattew W. Magic and magicians in the greco-roman world. London: Routledge, 2003.

FRAZER, Sir James George. O ramo de ouro. Rio de Janeiro: Editora Guanabara S. A. 1982.

GORDON, Richard. Magias imitativas grega e romana. In: . Bruxaria e Magia na Europa: Grécia antiga e Roma. São Paulo: Madras, 2004, p. 159-232.

GRAF, Fritz. La magie dans l'antiquité gréco-romaine. Paris: Les Belles Lettres, 1994.

GRIMAL, Pierre. Dictionnaire de la mythologie grecque et romaine. Paris: PUF, 1982. 
HERÔDOTO. História. Intr. e Trad. de Mario da Gama Kury. Brasília: Universidade de Brasília, 1988.

HOMÈRE. Iliade. Paris: Les Belles Lettres, 1956.

The Odyssey. London: Loeb Classical Library, 1976.

LESKY, A. Historia de la literatura griega. Madrid: Gredos, 1969.

LUCK, Georg. Bruxos, bruxas e feiticeiros na literatura clássica. In: GORDON, Richard. Bruxaria e magia na Europa: Grécia antiga e Roma. São Paulo: Madras, 2004, p. 103-156.

Arcana Mundi: Magia y ciencias ocultas em el mundo griego y romano.

Madrid: Gredos, 1985.

MARVIN, Meyer; MIKECKI, Paul (Org.). Ancient Magic and Ritual Power. New York: Köln (EJ Brill), 1995.

PLATON. Les Lois. Texte établi et traduit par Auguste Diés. Paris: Les Belles Lettres, 1956. 1967.

Théétete. Texte établi et traduit par Auguste Diès. Paris: Les Belles Lettres,

SEGALEN, Martine. Ritos e rituais. Portugal: Publicações EuropaAmérica, 2000.

TUPET, A.M. La magie dans la poésie latine: Des origines à la fin du régne d'Auguste. Paris: Les Belles Lettres, 1976. 